\title{
Dynamic tracking of manganese uptake in mouse hearts by rapid multi-slice $T_{1}$ mapping
}

Kai Jiang, Xin Yu

From 17th Annual SCMR Scientific Sessions

New Orleans, LA, USA. 16-19 January 2014

\section{Background}

Manganese $\left(\mathrm{Mn}^{2+}\right)$-enhanced MRI (MEMRI) has the potential for in vivo assessment of the voltage-gated L-type $\mathrm{Ca}^{2+}$ channel activity. Quantitative assessment of $\mathrm{Mn}^{2+}$ uptake via $\mathrm{Ca}^{2+}$ channels requires fast and accurate $\mathrm{T}_{1}$ mapping. In the current study, a multi-slice saturation recovery Look-Locker (MSRLL) method was developed for $\mathrm{T}_{1}$ mapping of the whole mouse heart in $<3$ min.

\section{Methods}

MSRLL Sequence

A schematic diagram of the MSRLL pulse sequence is shown in Figure 1. An ECG-triggered saturation module was applied at the beginning of each phase-encoding step, followed by the acquisition of k-space lines along the magnetization recovery curve in multiple slices. ECG-triggered image acquisition was performed at late diastole.

\section{Phantom Study}

All MRI studies were performed on a horizontal 7.0T Bruker scanner with a $35 \mathrm{~mm}$ volume coil. The MSRLL method was first validated in vitro using a multicompartment phantom with $\mathrm{MnCl}_{2}$ solution ranging from $30 \mu \mathrm{M}$ to $1000 \mu \mathrm{M}$. $\mathrm{T}_{1}$ maps of 5 slices were compared with those acquired with a previously validated single-slice method (SRLL). Imaging parameters were: flip

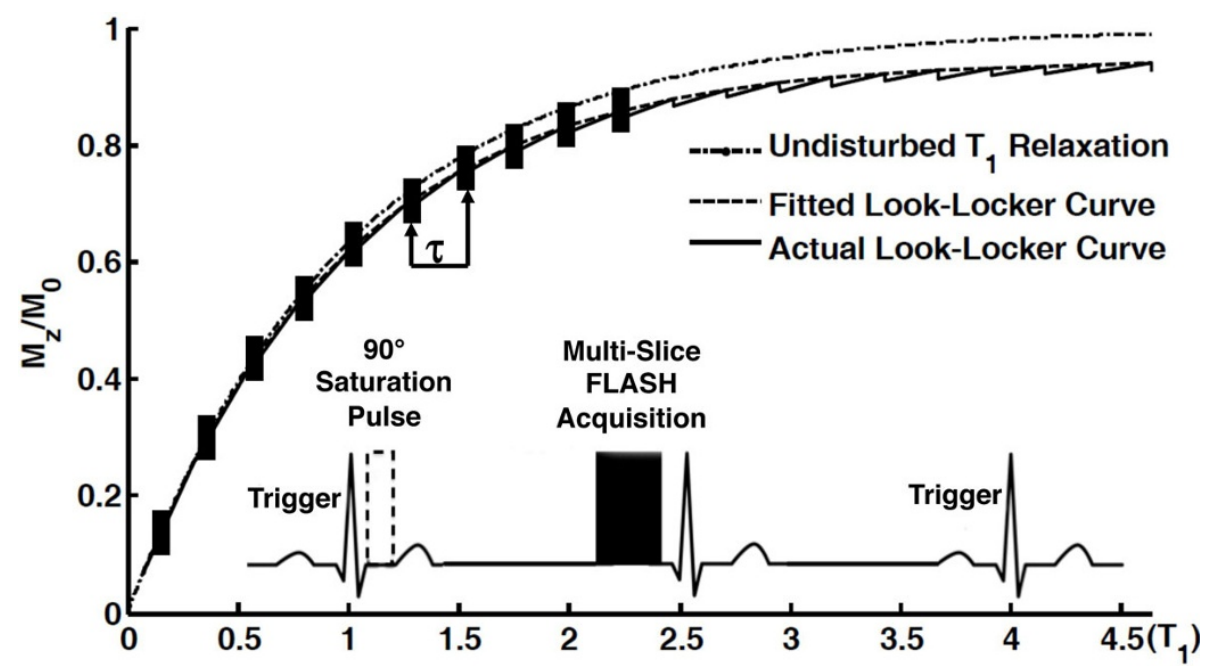

Figure 1 MSRLL pulse sequence. After $90^{\circ}$ non-slice selective saturation pulses, 10 sequential multi-slice FLASH acquisitions separated by an interval $\tau$ were applied. Each block on the relaxation curve represents a multi-slice acquisition module. 
angle, $10^{\circ}$; TE, $1.9 \mathrm{msec}$; slice thickness, $1 \mathrm{~mm}$; number of average, 1 ; field of view, $3 \times 3 \mathrm{~cm}^{2}$; matrix size, $128 \times 64$.

\section{In Vivo Study}

In vivo MEMRI studies were performed in 3-month-old FVB mice $(n=19)$. $T_{1}$ maps of three adjacent short-axis slices at mid-ventricular levels were acquired with the same imaging parameters as those used in vitro. Continuous $T_{1}$ mapping was performed during the $30 \mathrm{~min}$ of $\mathrm{MnCl}_{2}$ infusion through tail vein $(0.2 \mathrm{~mL} / \mathrm{hr})$ and the 15 minutes washout. To investigate the $\mathrm{Mn}^{2+}$-induced relaxivity changes, two different $\mathrm{MnCl}_{2}$ solutions at
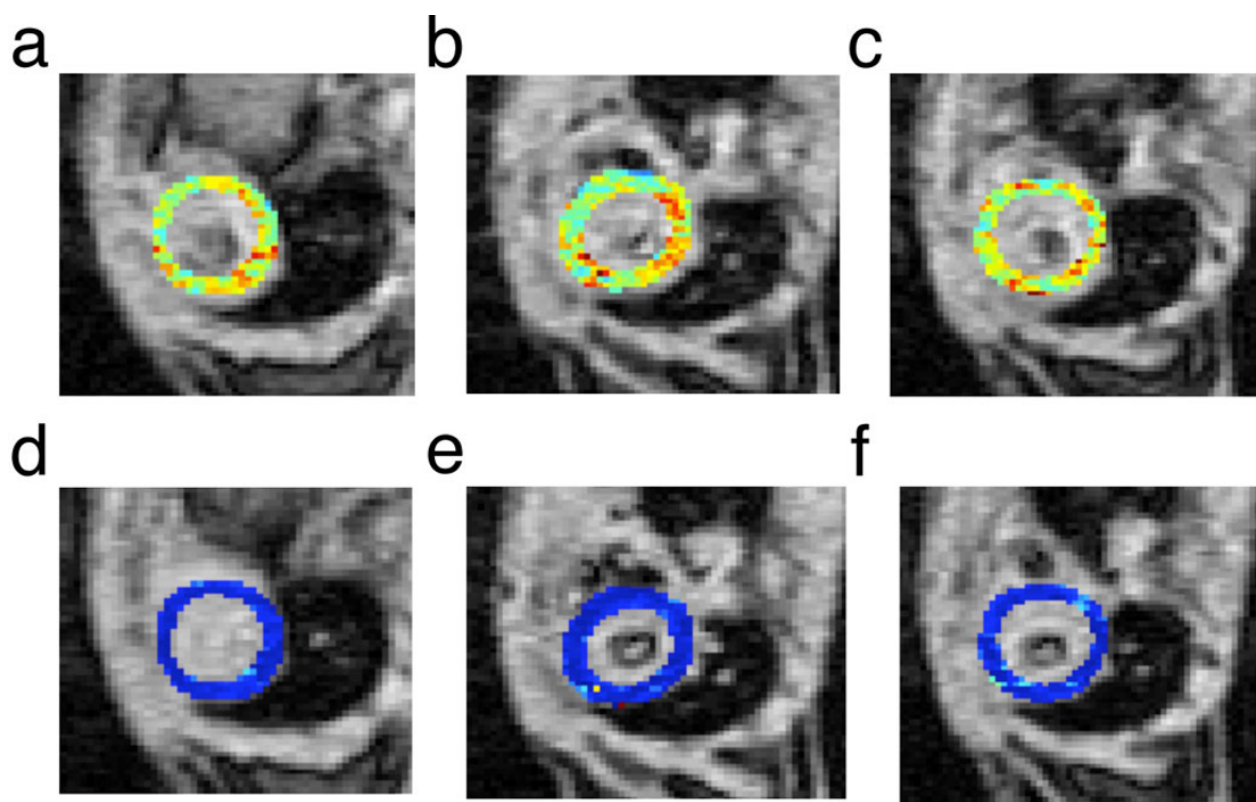

e
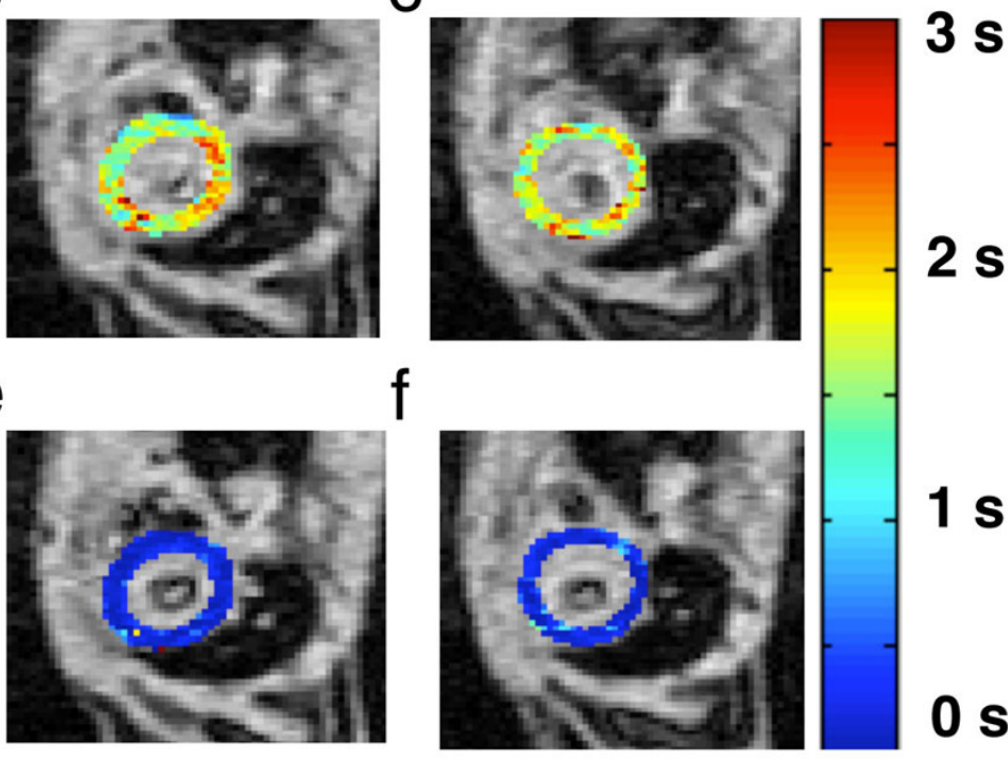

$2 \mathrm{~s}$

9

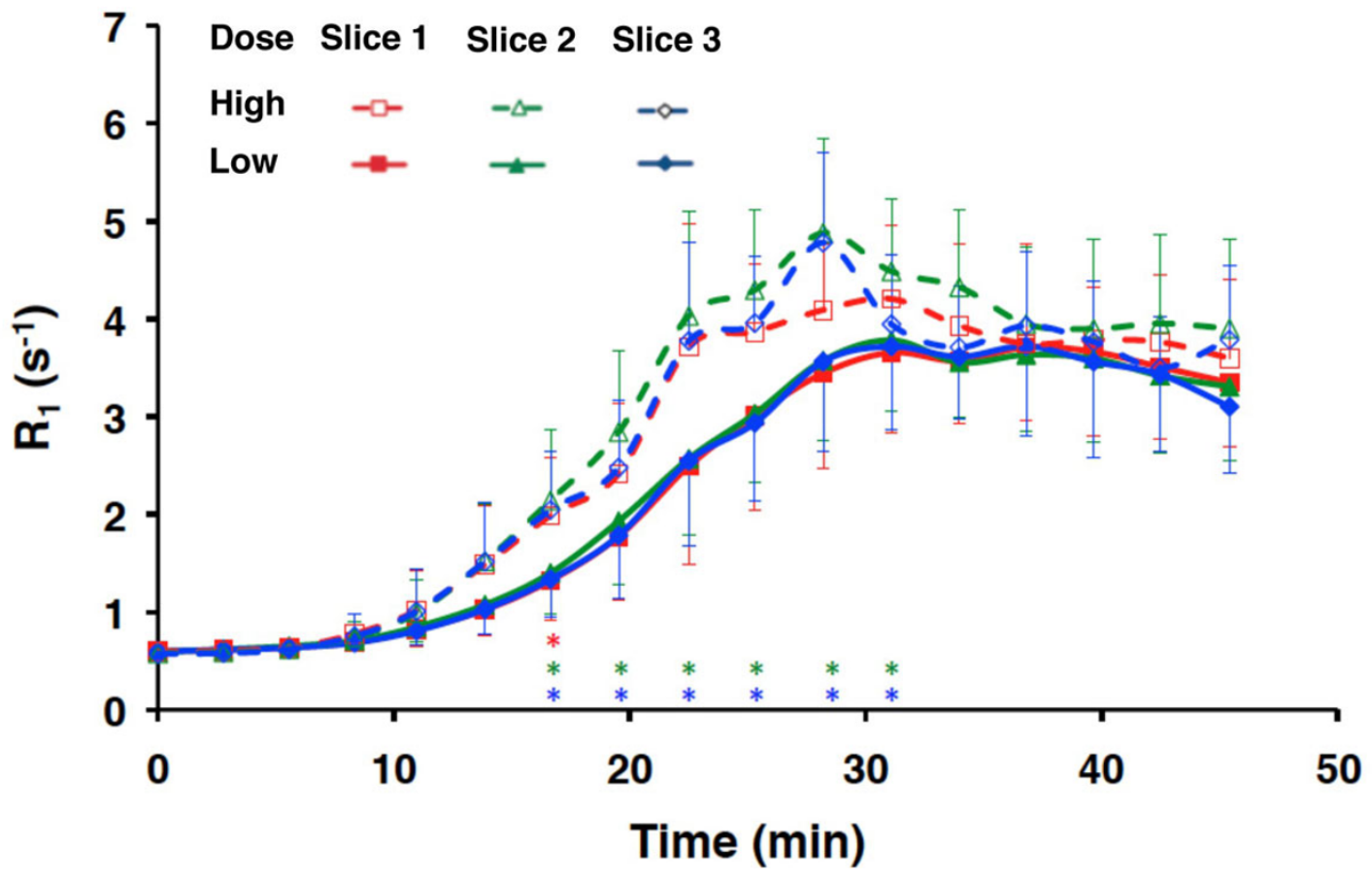

Figure $\mathbf{2} \mathbf{R}_{\mathbf{1}}$ changes in dynamic MEMRI study. a-c. Pre-contrast $T_{1}$ maps of the three slices. $d$-f. Post-contrast $T_{1}$ maps of the three slices. $g$. Time courses of $R_{1}$ changes. 
$126 \mathrm{mM}(\mathrm{n}=9)$ and $63 \mathrm{mM}(\mathrm{n}=10)$ were used. Validation study was performed either at baseline $(n=10)$ or post-contrast $(\mathrm{n}=10)$.

\section{Results}

In vitro studies showed strong agreement between MSRLL and SRLL. Average imaging time in vivo was 140 166 s. Shown in Figure 2 are representative $T_{1}$ maps acquired at baseline (Figure 2a-c) and after $\mathrm{Mn}^{2+}$ infusion (Figure $2 \mathrm{~d}-\mathrm{f}$ ). All three slices showed significant reduction in $\mathrm{T}_{1}$ after $\mathrm{Mn}^{2+}$ infusion. The time courses of the $R_{1}$ changes for all three slices are presented in Figure $2 \mathrm{~g}$. In general, higher $\mathrm{Mn}^{2+}$ dose induced larger increase in $\mathrm{R}_{1}$ during $\mathrm{Mn}^{2+}$ infusion.

\section{Conclusions}

An ECG-triggered, multi-slice saturation-recovery LookLocker method was developed for fast and complete cardiac $T_{1}$ mapping in mice. Validity and utility of this method was well demonstrated in the phantom and in vivo two-dose MEMRI studies.

\section{Funding}

This study was supported by NIH Grants HL73315 and HL86935 (Yu).

Published: 16 January 2014

Cite this article as: Jiang and $Y u$ : Dynamic tracking of manganese

uptake in mouse hearts by rapid multi-slice $T_{1}$ mapping. Journal of Cardiovascular Magnetic Resonance 2014 16(Suppl 1):W35.

Submit your next manuscript to BioMed Central and take full advantage of:

- Convenient online submission

- Thorough peer review

- No space constraints or color figure charges

- Immediate publication on acceptance

- Inclusion in PubMed, CAS, Scopus and Google Scholar

- Research which is freely available for redistribution

Submit your manuscript at www.biomedcentral.com/submit
C Biomed Central 